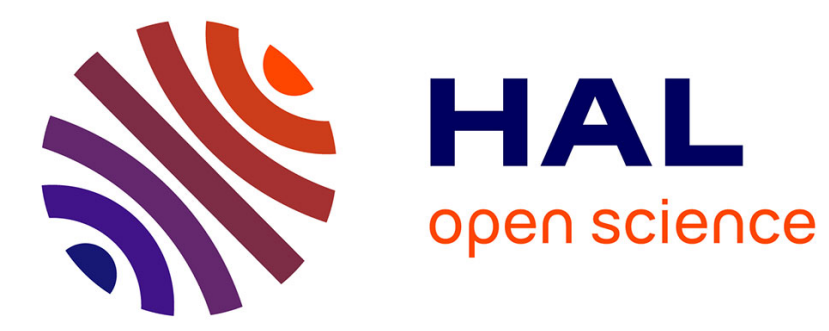

\title{
Cyclooxygenase-2-derived prostanoids reduce inward arterial remodeling induced by blood flow reduction in old obese Zucker rat mesenteric arteries
}

\author{
Emilie Vessières, Eric J. Belin de Chantemèle, Anne-Laure Guihot, Alain \\ Jardel, Bertrand Toutain, Laurent Loufrani, Daniel Henrion
}

\section{To cite this version:}

Emilie Vessières, Eric J. Belin de Chantemèle, Anne-Laure Guihot, Alain Jardel, Bertrand Toutain, et al.. Cyclooxygenase-2-derived prostanoids reduce inward arterial remodeling induced by blood flow reduction in old obese Zucker rat mesenteric arteries. Vascular Pharmacology, 2013, 58 (5-6), pp.356-362. 10.1016/j.vph.2013.03.001 . hal-02347292

\section{HAL Id: hal-02347292 \\ https://hal.science/hal-02347292}

Submitted on 14 Mar 2020

HAL is a multi-disciplinary open access archive for the deposit and dissemination of scientific research documents, whether they are published or not. The documents may come from teaching and research institutions in France or abroad, or from public or private research centers.
L'archive ouverte pluridisciplinaire HAL, est destinée au dépôt et à la diffusion de documents scientifiques de niveau recherche, publiés ou non, émanant des établissements d'enseignement et de recherche français ou étrangers, des laboratoires publics ou privés. 


\title{
Cyclooxygenase-2-derived prostanoids reduce inward arterial remodeling induced by blood flow reduction in old obese Zucker rat mesenteric arteries
}

\author{
Emilie Vessières ${ }^{\mathrm{d}}$, Eric J. Belin de Chantemèle ${ }^{\mathrm{a}}$, Anne-Laure Guihot ${ }^{\mathrm{b}}$, Alain Jardel ${ }^{\mathrm{a}}$, Bertrand Toutain ${ }^{\mathrm{a}}$, \\ Laurent Loufrani ${ }^{\mathrm{b}, \mathrm{d}}$, Daniel Henrion ${ }^{\mathrm{c}, \mathrm{d}, *}$
}

a Angers University, Angers, France

${ }^{\mathrm{b}}$ CNRS UMR 6214, Angers, France

c INSERM UMR-S1083, Angers, France

d $\mathrm{CHU}$ Angers, Angers, France

Obesity is associated with altered arterial structure and function leading to arterial narrowing in most vascu-lar beds, especially when associated with aging. Nevertheless, mesenteric blood flow remains elevated in obese rats, although the effect of aging remains unknown. We investigated mesenteric artery narrowing fol-lowing blood flow reduction in vivo in 3- and 12-month-old obese Zucker rats.

After 21 days, inward remodeling occurred in low flow (LF) arteries in young and old lean rats and in young obese rats (30\% diameter reduction). Diameter did not significantly decrease in old obese rats. Phenylephrine-mediated contraction was reduced by approximately $20 \%$ in LF arteries in all groups but in old obese rat arteries in which the decrease reached $80 \%$. LF arteries expressed cyclooxygenase-2 and blood 6-keto-PGF1alpha (prostacyclin metabolite) was elevated in old obese rats. In old obese rats, acute cyclooxygenase-2 blockade restored phenylephrine-mediated contraction in LF arteries and chronic cyclooxygenase-2 blockade restored inward remodeling and contractility to control level.

Thus, in old obese rats, cyclooxygenase-2-derived prostacyclin prevented the diameter reduction induced by a chronic decrease in blood flow. This adaptation is in favor of a preserved perfusion of the mesentery by con-trast with other vascular territories, possibly amplifying the vascular disorders occurring in obesity.

\section{Introduction}

The metabolic syndrome is a major health problem affecting a large proportion of the population worldwide. Its incidence increases in parallel to the enhanced prevalence of obesity and diabetes (Herman and Zimmet, 2012; Rao et al., 2012; Wild et al., 2004). The metabolic syndrome is associated with an increasing risk of overall mortality as well as cardiovascular morbidity and mortality (Hu et al., 2004). It is defined as an association of three or more of the following risk factors: impaired glucose tolerance or insulin resistance, increased blood pressure, increased plasma triglycerides and/or low HDL cholesterol, obesity, microalbuminuria (Alberti and Zimmet, 1998; Onat, 2011; Prasad et al., 2012). The metabolic syndrome is associated with endothelial dysfunction (Goodwill and Frisbee, 2012; Thomas et al., 2004) and vascular remodeling (Rocic, 2012) leading

\footnotetext{
* Corresponding author at: Dept of Integrated Neurovascular and Mitochondrial Biology, UMR CNRS 6214-INSERM UMRS1083, Faculté de Médecine, 49045 Angers, France. Tel.: +332417358 45; fax: + 33241735895 .

E-mail address: daniel.henrion@inserm.fr (D. Henrion).

URL: http://www.bnmi.fr (D. Henrion).
}

to arterial wall hypertrophy (Iannuzzi et al., 2005). This vascular dysfunction is most likely involved in the higher incidence of end-organ damage in patients with metabolic syndrome.

Resistance arteries play a key role in the control of local blood flow and their capacity to adapt in response to chronic changes in blood flow is essential after ischemia as well as in response to exercise (Henrion, 2005; van den Akker et al., 2009; Vessieres et al., 2012). In obese Zucker rats (OZR), vasoconstrictor tone increases and NO-dependent dilation decreases in the renal circulation (Stepp et al., 2007). By contrast, blood flow in the mesenteric circulation is higher in OZR than in lean animals (Enevoldsen et al., 2000; Romanko and Stepp, 2005). Despite reduced NO-dependent dilation in OZR mesenteric arteries (Bouvet et al., 2007; Romanko and Stepp, 2005), vasoconstrictor tone is also reduced, thus preserving mesenteric blood flow in hyperphagic rats (Romanko and Stepp, 2005). We have recently shown that the diameter enlargement induced by a chronic increase in blood flow, which is impaired in one-year old lean rats, is maintained in old OZR (Belin de Chantemele et al., 2010). This finding suggests that OZR mesenteric arteries remain able to further enlarge and thus to support higher blood flow. Nevertheless, when metabolic syndrome develops with age, rats become heavier with more fat, especially in the mesentery and they become 
moderately, although significantly, hypertensive and diabetic (Belin de Chantemele et al., 2010). In these conditions blood flow in mesenteric arteries, unlike in other vascular beds, should decrease and thus arteries should undergo inward remodeling as observed in both hypertension (Prewitt et al., 2002) and diabetes (Schofield et al., 2002). Nevertheless, inward remodeling depends on the basal constrictor tone of the arteries and the local inflammation affecting the mesentery might maintain an excessive vasodilatation. Thus, we investigated the effect of aging and metabolic syndrome on the capacity of mesenteric arteries to develop inward eutrophic remodeling in response to a chronic decrease in blood flow. Young and old obese Zucker rats (OZR) were used as a model of metabolic syndrome.

We used a model previously described (Freidja et al., 2012; Loufrani et al., 2002a; Pourageaud and De Mey, 1997; Tarhouni et al., 2013) based on ligation of mesenteric arteries. This model allows the comparison of resistance arteries submitted chronically to low or normal blood flow in the same vascular bed and in the same physiological conditions in vivo. Blood flow decreases by $80 \%$ in the ligated arteries leading to inward eutrophic remodeling (Belin de Chantemele et al., 2009; Freidja et al., 2011; Loufrani et al., 2002b). We used 12-month old obese Zucker rats, which are relatively old as they have a limited life expectancy (Johnson et al., 1997).

\section{Materials and methods}

\subsection{Animals}

The procedure followed in the care and euthanasia of the study animals was in accordance with the European Community Standards on the Care and Use of Laboratory Animals (Ministère de l'Agriculture, France, authorization No. 6422). The protocol is approved by the Committee on the Ethics of Animal Experiments of the "Pays de la Loire" Region ("Comité d'éthique en Expérimentation Animale", CEEA, permit \# CEEA PdL 2008.10).

Three and 12-month old male obese Zucker rats (OZR) and lean Zucker rats (Charles River, L'Arbresles, France) were anesthetized (isoflurane, 2.5\%) and pre-treated with buprenorphine (Temgesic ${ }^{\circledR}$; $0.1 \mathrm{mg} / \mathrm{kg}$, s.c.). A loop of intestine was then exposed and local mesenteric artery blood flow was surgically reduced, as previously described (Belin de Chantemele et al., 2009). The ligated artery was designed as low flow (LF) arteries. Other arteries located at the distance of the ligated arteries were used as control arteries (normal flow, NF).

Twenty-one days after surgery, animals were anesthetized (Isoflurane, 2.5\%). The left femoral artery was cannulated for blood pressure measurement as previously described (Driss et al., 2000). Blood samples were then collected and the rats were sacrificed by $\mathrm{CO}_{2}$ inhalation. The gut was excised and the mesenteric arteries were gently dissected. From each rat, LF and NF arteries were isolated and divided in several segments used respectively for pressure-diameter relationship measurement, pharmacology as well as for immunohistological and biochemical analyses. Twelve rats were used per group and each experiment described below was performed on a different segment of artery obtained from each animal.

In another series of experiments, 12-month-old lean rats and OZR were treated with the COX-2 inhibitor celecoxib $(25 \mathrm{mg} / \mathrm{kg}$, forced feeding, twice daily) (Belin de Chantemele et al., 2010).

\subsection{Blood and plasmatic parameters}

Before sacrifice, glycemia was quantified on a sample of arterial blood with a glucometer as previously described (Belin de Chantemele et al., 2010). Plasma dinor-6-keto PGF1alpha was then determined as previously described (Retailleau et al., 2010) using a commercially available kit (Cayman).
2.3. Pressure-diameter relationship and histomorphometry in isolated arteries

Arterial segments were cannulated at both ends and mounted in a video monitored perfusion system as previously described (Bolla et al., 2002; Retailleau et al., 2013). Briefly, cannulated arterial segments were bathed in a $5 \mathrm{ml}$ organ bath containing a $\mathrm{Ca}^{2+}$-free physiological salt solution containing ethylenbis-(oxyethylenenitrolo) tetra-acetic acid (EGTA, $2 \mathrm{mmol} / \mathrm{L}$ ) and sodium nitroprusside (10 $\mu \mathrm{mol} / \mathrm{L})$. Pressure steps (10 to $150 \mathrm{~mm} \mathrm{Hg}$ ) were then performed in order to determine passive arterial diameter. Pressure and diameter measurements were collected using a Biopac data acquisition system (Biopac MP100 and Acqknowledge ${ }^{\circledR}$ software; La Jolla, CA, USA). The arterial segment was then fixed with formaldehyde under a pressure of $75 \mathrm{~mm} \mathrm{Hg}$ in order to measure media cross-section area and wall thickness as previously described (Loufrani et al., 2002b).

\subsection{Contractility of isolated mesenteric arteries}

Other segments of LF and NF mesenteric arteries (2 mm long) were mounted on a wire-myograph (DMT, Aarhus, DK) as previously described (Henrion et al., 1992). Briefly, 2 tungsten wires (40 $\mu \mathrm{m}$ in diameter) were inserted into the lumen of the arteries and fixed to a force transducer and a micrometer, respectively. Arteries were bathed in a physiological salt solution. Wall tension was applied as described previously (Dowell et al., 1996).

Cumulative concentration-response curve (CRC) to phenylephrine $(0.001$ to $10 \mu \mathrm{mol} / \mathrm{L})$ was performed before and after incubation with the cyclooxygenase inhibitor indomethacin $(10 \mu \mathrm{mol} / \mathrm{L}, 20 \mathrm{~min})$ or with the selective COX-2 inhibitor NS398 (10 $\mu \mathrm{mol} / \mathrm{L}, 20 \mathrm{~min})$ (Henrion et al., 1996).

\subsection{Western blot analysis}

Other arterial segments were pooled and then homogenized. Proteins ( $25 \mu \mathrm{g}$ total protein from each sample) were separated by SDS-PAGE using a $4 \%$ stacking gel followed by a $10 \%$ running gel. Proteins were detected with specific antibodies (Santa Cruz Biotechnology, COX-2 1:500, sc-1746 and beta-actin 1:1000 in TBST). Protein expression was visualized using the Luminol Reagent (Santa Cruz Biotechnology) (Baron-Menguy et al., 2010).

\subsection{Immunohistological analysis of $\mathrm{COX}-2$}

Arterial segments were mounted in embedding medium (Tissu-Tek, Miles, Inc), frozen in isopentane pre-cooled in liquid nitrogen, and stored at $-80{ }^{\circ} \mathrm{C}$. COX-2 was detected on transverse cross sections ( $7 \mu \mathrm{m}$ thick) using primary goat anti-COX-2 polyclonal antibodies (1/100, Santa Cruz Biotechnology, sc-1747) followed by the fluorescent secondary antibody ( $1 / 200$, Fluoroprobes) as previously shown (Retailleau et al., 2010). In negative control experiments the primary antibody was omitted. A positive control experiment was performed using a similar artery obtained from a rat treated with lipopolysaccharide.

\subsection{Statistical analysis}

Results are expressed as means \pm SEM. Significance of the difference between arteries was determined by ANOVA (1-factor ANOVA or ANOVA for consecutive measurements, when appropriate). Means were compared by paired $t$-test or by the Bonferroni test for multigroup comparisons. Values of $\mathrm{P}<0.05$ were considered to be significant. 


\section{Results}

\subsection{Physiological parameters}

Rat body weight was significantly higher in OZR than in lean rats and higher in old than in young animals ( $527 \pm 28$ versus $335 \pm$ $11 \mathrm{~g}$ in young rats; $694 \pm 35$ versus $456 \pm 28 \mathrm{~g}$ in old rats). Mean arterial blood pressure was slightly, but significantly, higher in old OZR than in old lean rats ( $130 \pm 7$ versus $106 \pm 5 \mathrm{~mm} \mathrm{Hg}$, no significant difference between lean rats and OZR in young animals).

\subsection{Pressure-diameter relationship in isolated mesenteric arteries}

Stepwise increases in pressure induced a significant rise in luminal arterial diameter in mesenteric arteries (Fig. 1A, B). Twenty-one days after ligation arterial diameter in LF arteries was significantly lower compared to NF arteries in both OZR and lean rats (Fig. 1C, D). Nevertheless, the reduction in diameter found in LF arteries from old OZR was significantly lower than in old lean rats and in young animals (Fig. 1D).

Media cross-section (Fig. 1E) was lower in LF than in NF arteries in all groups but in old OZR. Media cross-section was also higher in OZR than in lean rats and in 12-month old rats than in 3-month old animals (Fig. 1E).

\subsection{Arterial contractility}

As inward remodeling of LF arteries relies on the capacity of the arteries to contract, we tested phenylephrine-mediated contraction in the different groups of rats. Phenylephrine induced contraction in isolated mesenteric resistance arteries (Fig. 2A-D). Phenylephrine-mediated contraction was lower in LF than in NF arteries in both lean and obese

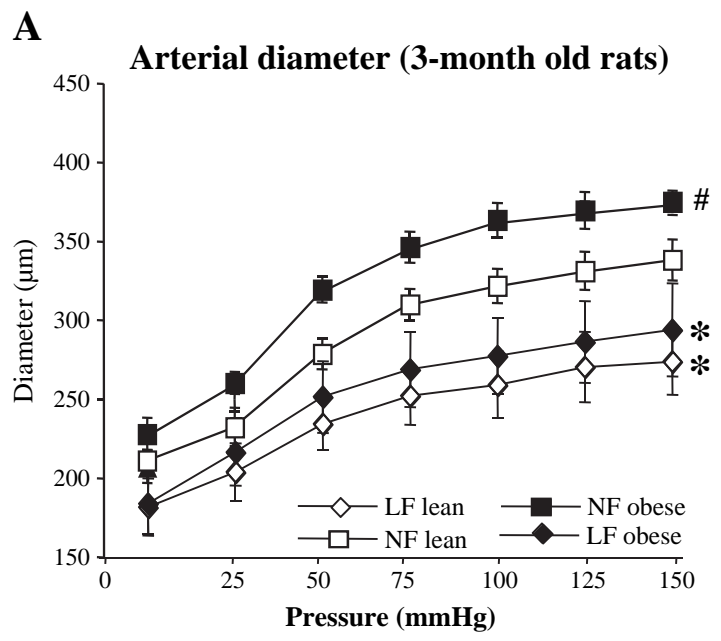

\section{B}

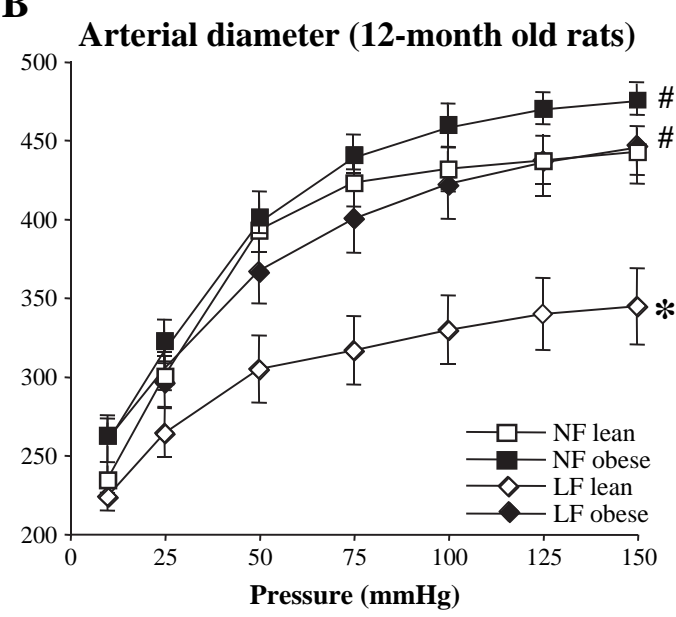

C

\% change HF versus NF artery

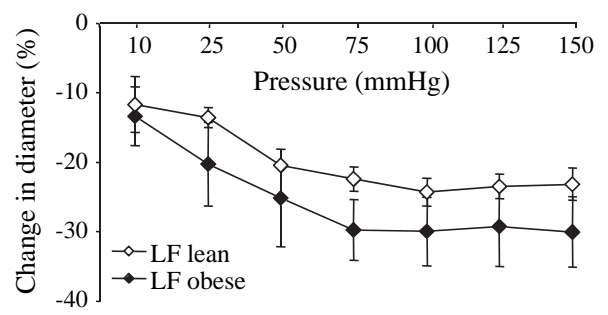

D

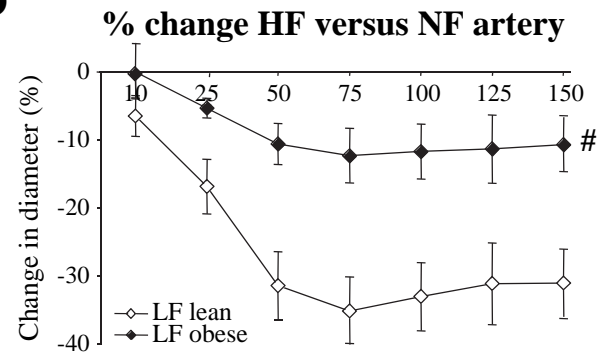

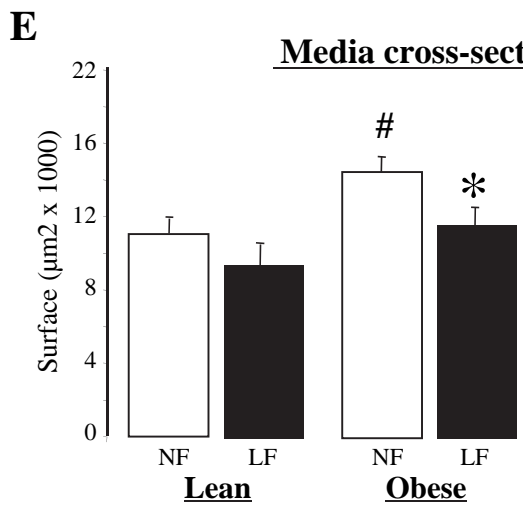

3-month old rats

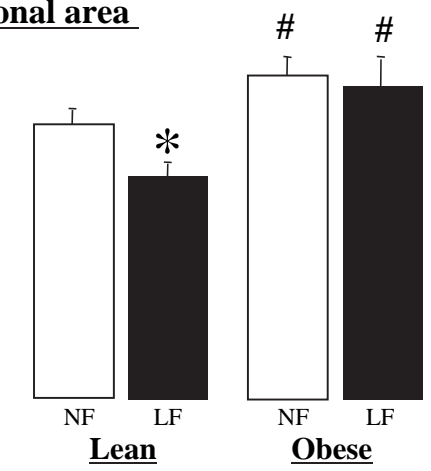

12-month old rats

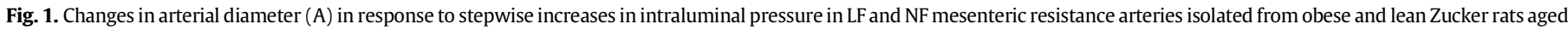

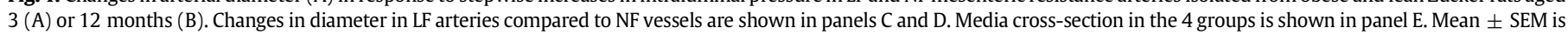
presented ( $\mathrm{n}=12$ rats per group). ${ }^{*} \mathrm{P}<0.01$, LF versus $\mathrm{NF}$ in each group. $\# \mathrm{P}<0.01$, obese versus lean. 
rats, irrespective of age (Fig. 2A). In LF arteries of 12-month old rats, phenylephrine-mediated contraction was significantly lower in obese than in lean rats.

Indomethacin did not significantly affect phenylephrine-mediated contraction in all groups (Fig. 3A, B), except in 12-month-old OZR in which indomethacin improved the contraction (Fig. 3B, right panel), suggesting the involvement of a dilator prostanoid. As COX-2 expression has been shown in aging as well as in diabetes (Gendron et al., 2007; Retailleau et al., 2010), we investigated its role in LF remodeling.

\subsection{Involvement of $\mathrm{COX}-2$}

The presence of COX-2 in obese rats was evidenced first using immunohistochemistry. COX-2 was observed in NF and LF arteries in 12-month old OZR but not in lean 12-month old rats (Fig. 4A, B). No COX-2 was found in young rats (data not shown). The presence of COX-2 in old OZR was confirmed using Western-blot analysis (Fig. 4CD).

As the effect of indomethacin on phenylephrine-induced contraction in LF arteries of old OZR was in favor of the production of vasodilator COX-derivatives, we measured plasma 6-keto-PGF1alpha. This latter was significantly greater in 12-month old OZR than in the other groups of rats (Fig. 4E). Twelve-month old OZR were then treated chronically with the COX-2 blocker celecoxib. In this group plasma 6-ketoPGF1alpha was not different from the level found in 3-month old rats (lean or obese) (Fig. 4E).

As COX-2 was found in mesenteric arteries of 12-month old OZR, we determined the effect of blocking acutely the enzyme with NS398 on vascular reactivity. The acute application of NS398 significantly

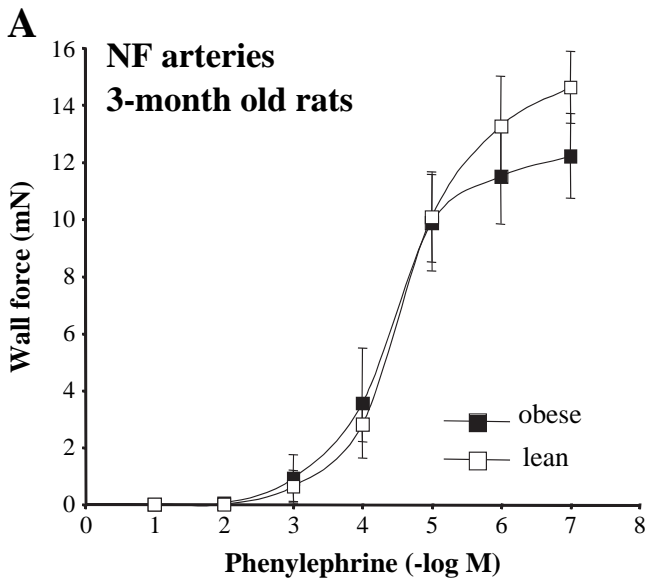

C

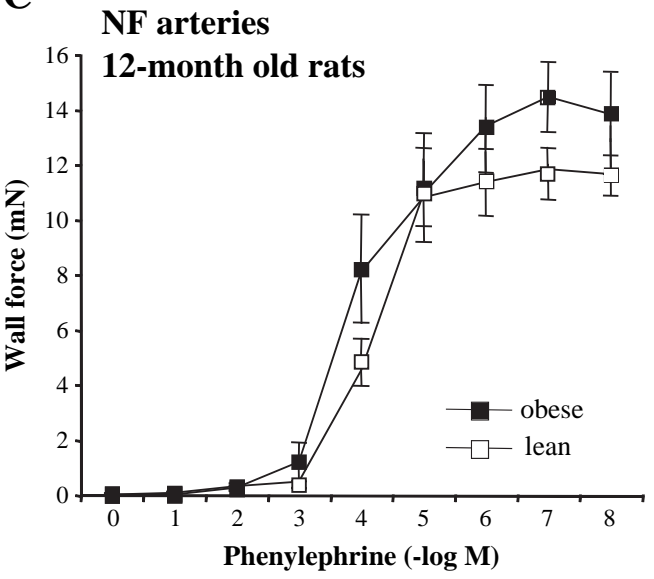

increased phenylephrine-induced contraction in LF arteries isolated from 12-month-old OZR (Fig. 5). In 12-month-old lean rats, acute NS398 had no significant effect on phenylephrine-induced contraction in NF and LF arteries (Fig. 5). Acute NS398 did not affect the contraction in 3-month-old rats (data not shown).

In 12-month old rats chronically treated with the COX-2 inhibitor celecoxib internal diameter was significantly lower in LF than in NF arteries in both lean rats and OZR (Fig. 6AB). Arterial diameter in LF arteries from OZR was not significantly different from that in obese rats suggesting that chronic COX-2 inhibition restored the capacity of the arteries to remodel in response to a chronic decrease in blood flow.

Media cross-section (Fig. 6C) in celecoxib-treated rats was lower in LF than in NF arteries.

Indomethacin had no further effect on phenylephrine-induced contraction (Fig. 6D) in 12-month old OZR treated chronically with celecoxib.

\section{Discussion}

We found that inward remodeling due to a chronic decrease in blood flow was reduced in 12-month-old obese Zucker rats. This was associated with COX-2 expression and COX-2-derived vasorelaxant agent production, possibly prostacyclin. The chronic blockade of COX-2 in 12-month-old OZR restored inward remodeling to control level.

The structural and functional adaptations of the microvasculature in response to chronic changes in blood flow have a major role in pathological processes such as hypertension, ischemic diseases and in metabolic disorders such as diabetes, obesity and in the metabolic syndrome (Freidja et al., 2012; Kauffenstein et al., 2012; Vessieres et

\section{B}

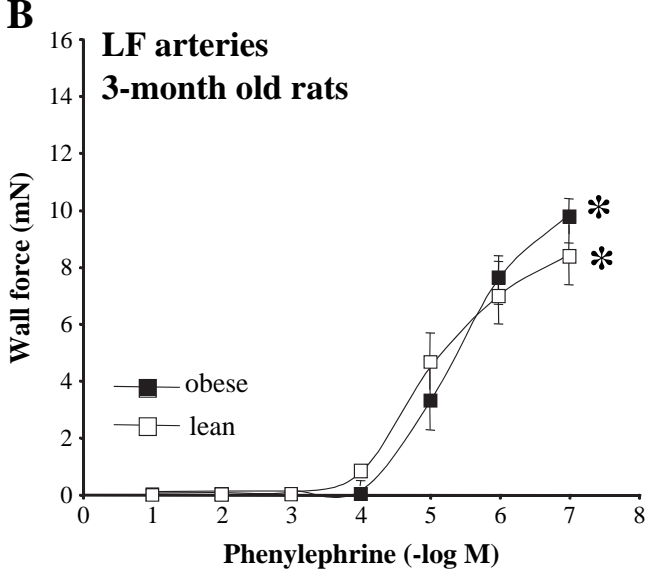

D

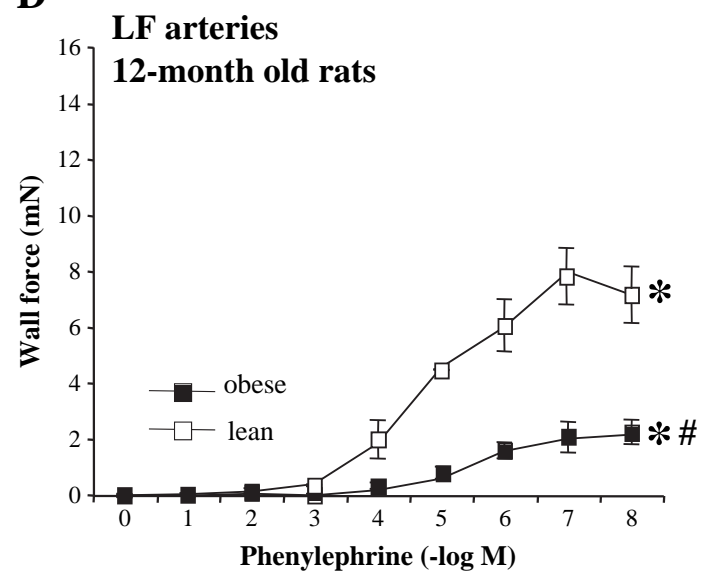

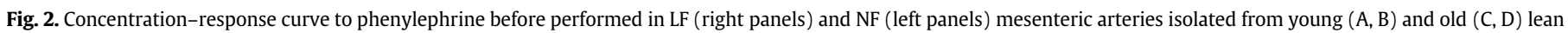
or obese Zucker rats. Mean \pm SEM is presented $\left(n=12\right.$ rats per group). ${ }^{*} \mathrm{P}<0.01$, LF versus $\mathrm{NF}$ in each group. \#P $<0.01$, obese versus lean. 
A

Phenylephrine $(1 \mu \mathrm{mol} / \mathrm{L})$ in 3-month old rats
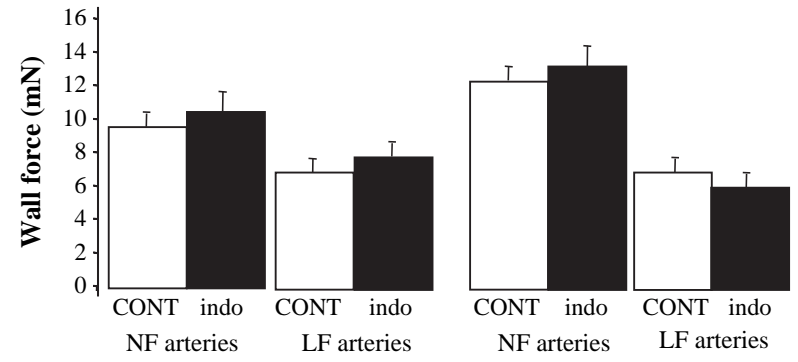

Lean rats

Obese Zucker rats

B

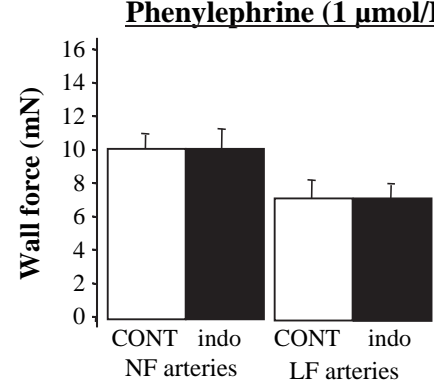

Lean rats

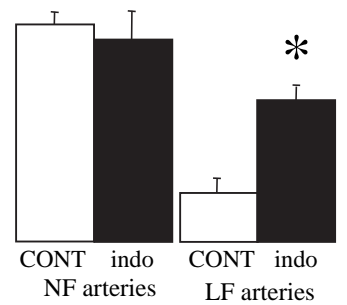

Obese Zucker rats
Fig. 3. Contraction induced by phenylephrine before (CONT) and after incubation with indomethacin (indo) performed in LF and NF mesenteric arteries isolated from young (A) and old (B) lean or obese Zucker rats. Mean \pm SEM is presented ( $\mathrm{n}=12$ rats per group). ${ }^{*} \mathrm{P}<0.01, \mathrm{LF}$ versus $\mathrm{NF}$ in each group.

al., 2012). The OZR becomes resistant to insulin, hypertensive, obese and dyslipidemic with vascular dysfunction. Thus, it is considered a good animal model to study the metabolic syndrome (Kurtz et al., 1989). In OZR, mesenteric arteries were submitted to a chronic decrease in blood flow, which has been previously shown to induce inward remodeling (Buus et al., 2001; Lemkens et al., 2012; Loufrani et al., 2002a; Pourageaud and De Mey, 1997; van den Akker et al., 2011). Inward remodeling is due to reduced endothelium stimulation leaving unbalanced local vasoconstrictor tone (Bakker et al., 2008; Baron-Menguy et al., 2010).

Inward remodeling occurred with similar amplitude in young and old lean rats with a similar decrease in phenylephrinedependent contraction. In young OZR, inward remodeling was identical to that found in lean animals. In old OZR inward remodeling was strongly reduced with both a lower diameter reduction (Fig. 1B) and no decrease in wall mass (Fig. 1C). In parallel, the associated decrease in phenylephrine-dependent contraction was more important in old OZR than in old lean and young rats. In old OZR indomethacin increased phenylephrine-induced contraction, suggesting the involvement of a vasodilator agent derived from the cyclooxygenase pathway. Furthermore, we found a significant COX-2 expression in old Zucker rats and the COX-2 inhibitor NS398 had the same effect than indomethacin, improving phenylephrine-dependent contraction in LF arteries of old obese Zucker rats. Furthermore, chronic COX-2 inhibition with celecoxib in old Zucker rats restored low flow remodeling to the level found in lean rats. The vasodilator produced by COX-2 might be prostacyclin as we found in the old obese Zucker rat a higher level of its stable metabolite 6-keto-PGF1alpha. Celecoxib reduced this excessive prostacyclin production. This in is agreement with the previous studies showing that COX-2 is expressed in old obese mice and produces vasodilator prostanoids (Gendron et al., 2007).

Although COX-2 blockade reduced 6-keto-PGF1alpha-blood level, mean arterial blood pressure was not affected suggesting that
A

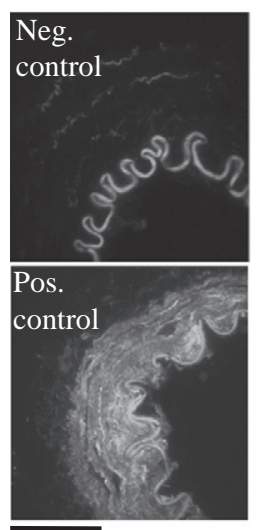

$50 \mu \mathrm{m}$

B

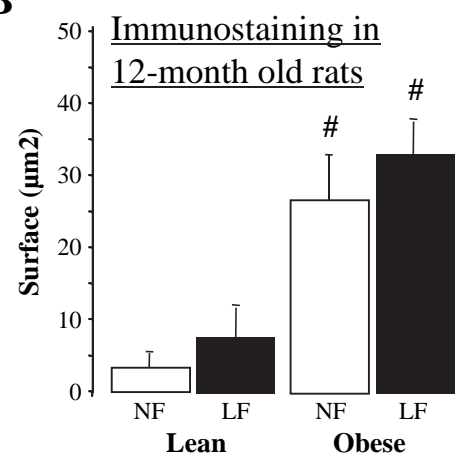

C

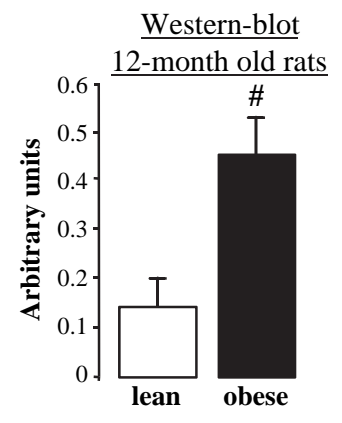

D

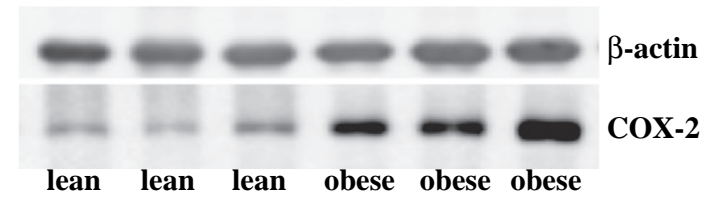

$\mathbf{E}$

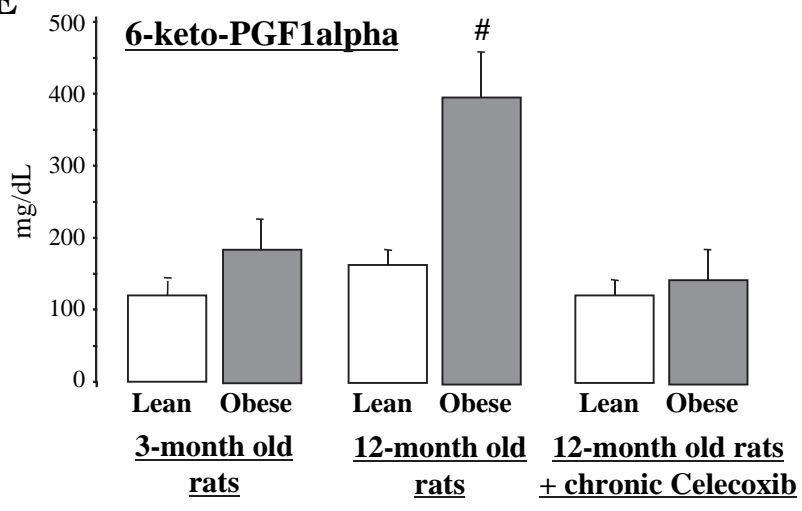

Fig. 4. COX-2 immunostaining (A) in LF and NF arteries from 12-month old lean and obese Zucker rats. Quantification of the fluorescence is shown in the bargraph (B). The presence of COX-2 in old obese Zucker rats was confirmed using Western-blot analysis (C) and typical blots are shown in D. Plasma 6-keto-PGF1alpha (E) was measured in 3-and 12-month old lean and obese Zucker rats and in 12-month-old rats chronically treated or not with NS398. Mean \pm SEM is presented $(n=12$ rats per group for the immunostaining and $\mathrm{n}=6$ rats per group for the Western blot analysis). \#P $<0.01$, obese versus lean.

prostacyclin has no role in systemic blood pressure control in old obese Zucker rats. This is in agreement with clinical observations showing that NSAIDs and COX2 inhibitors used chronically do not significantly increase systemic blood pressure (Morrison et al., 2007). Nevertheless, this does not exclude a role for prostanoids in local 


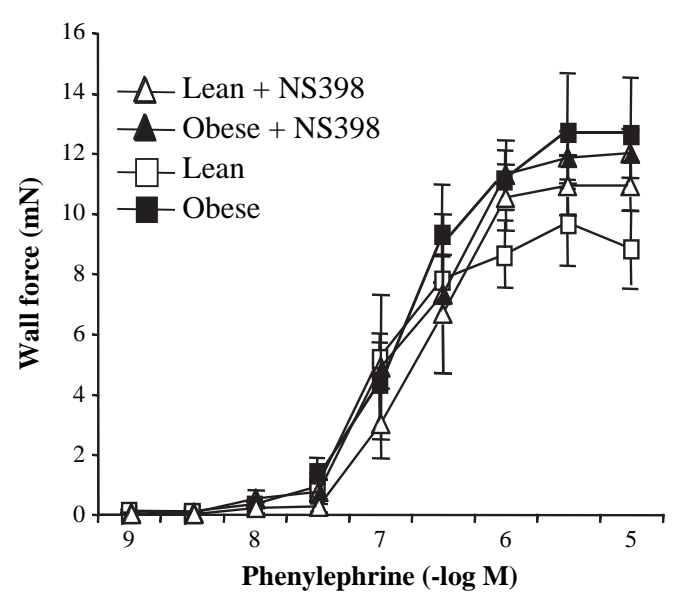

B

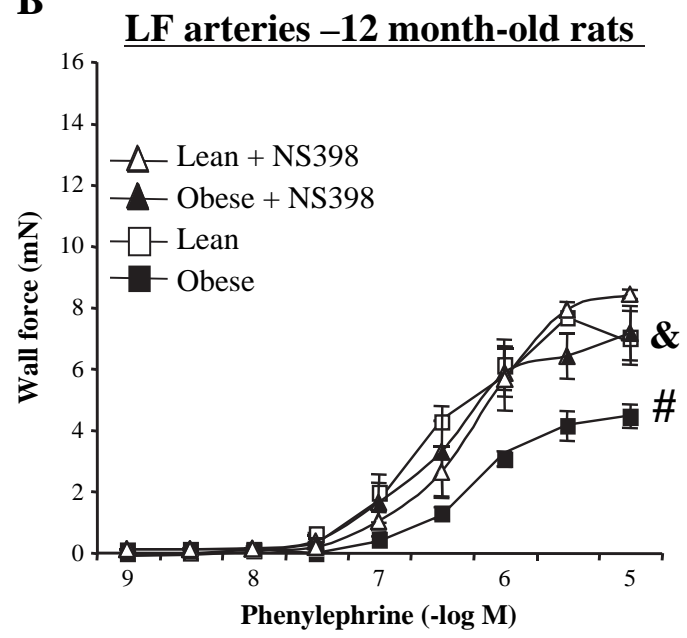

Fig. 5. Concentration-response curves to phenylephrine performed in the absence and in the presence of NS398 (10 $\mu \mathrm{mol} / \mathrm{L}, 20 \mathrm{~min})$ in NF (A) and LF (B) arteries isolated from 12-months old obese and lean Zucker rats. Mean \pm SEM is presented $(n=12$ rats per group). \#P $<0.01$, obese versus lean. \&P $<0.01$, effect of NS398.

blood flow control in a specific vascular territory as suggested by our findings. Indeed, in the course of aging there is a progressive reduction in the participation of NO and endothelium-derived hyperpolarizing factor in association with increased participation of cyclooxygenasederived prostanoids in endothelium-mediated dilation (Yildiz, 2007). Our finding is in agreement with previous observations showing that COX2-derived vasodilator prostanoids are involved in the control of vascular tone in renal (Gendron et al., 2007) and coronary arteries (Sanchez et al., 2010) in mice and rat models of obesity. On the other hand, in large arteries COX2-derived vasoconstrictor prostanoids increase tone as observed in high fat fed mice (Traupe et al., 2002). Nevertheless, in these studies, COX2-derived prostanoids contribute to acute changes in vascular tone whereas; we found in the present study that COX2-derived vasodilator prostanoids reduce inward remodeling in arteries chronically exposed to low blood flow. This maintenance of a larger arterial diameter in old OZR was not observed in other vascular territories where arterial narrowing usually occurs (Traupe et al., 2002). Interestingly, mesenteric blood flow is higher in OZR than in lean animals (Enevoldsen et al., 2000; Romanko and Stepp, 2005). A reduced vasoconstrictor tone in the mesenteric arteries (present study and (Romanko and Stepp, 2005)) is most likely the cause of this observation, thus preserving high mesenteric blood flow in hyperphagic rats. Maintaining a high blood flow in the mesenteric vascular bed could participate in the development of obesity.
A

\section{Celecoxib-treated 12-month-old rats}

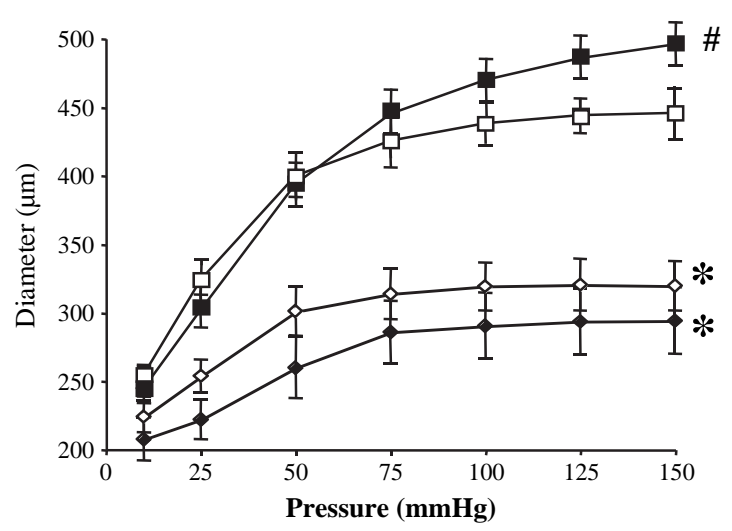

B

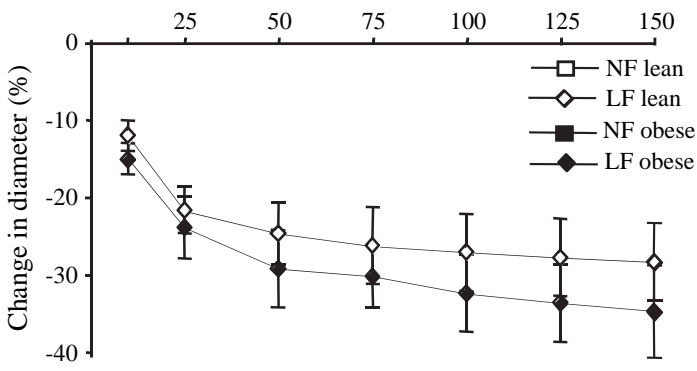

$\mathbf{C}$

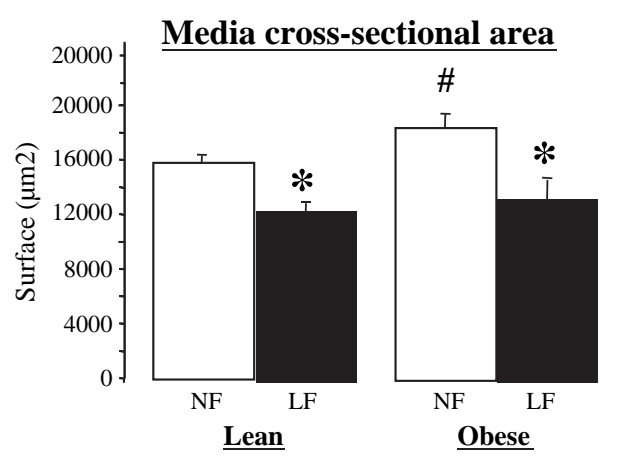

D Phenylephrine $(1 \mu \mathrm{mol} / \mathrm{L})$-mediated contraction

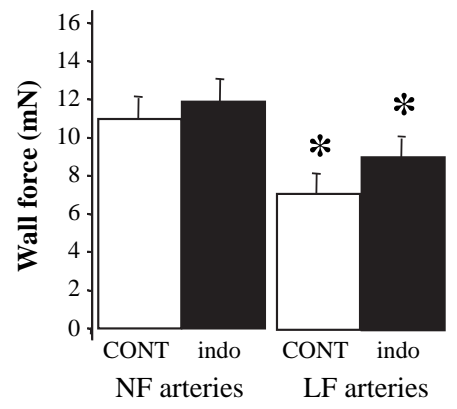

$\underline{\text { Lean rats }}$

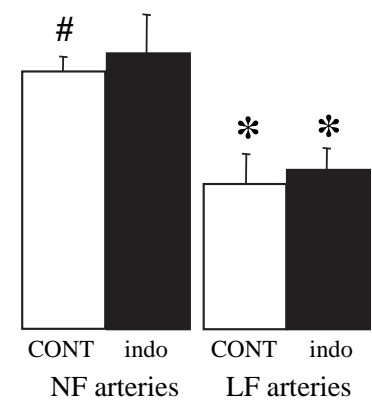

Obese Zucker rats
Fig. 6. Changes in diameter $(A)$ in responses to stepwise increases in pressure LF and $\mathrm{NF}$ mesenteric resistance arteries isolated from old obese and lean Zucker rats treated chronically with the COX-2 inhibitor celecoxib. Changes in diameter in LF arteries compared to NF vessels are shown in panel B and media cross sectional area in panel C. Phenylephrine-induced contraction (D) was measured before (control, CONT) and after application of indomethacin (indo). Data is shown as wall force. Mean \pm SEM is presented ( $\mathrm{n}=12$ rats per group). ${ }^{*} \mathrm{P}<0.01$, LF versus $\mathrm{NF}$ in each group. $\# \mathrm{P}<0.01$, obese versus lean. 
The current study predicts impaired microvascular regulation and structural abnormality during metabolic syndrome. Indeed, inward remodeling due to blood flow reduction is opposed by COX-2 derived vasodilator prostanoids in the mesenteric circulation in old obese Zucker rats. Our data suggest that COX2 maintains vasodilator tone in aging, probably participating, together with hyperphagia, to the progression of fat accumulation and obesity. Nevertheless caution should be taken as regard to a possible use of COX-2 inhibitors as they have been shown to exert deleterious adverse effects (Willette et al., 2009).

\section{Acknowledgments}

This work was supported in part by the Foundation for Medical Research (FRM: Fondation pour la Recherche Médicale), Paris, France.

\section{References}

Alberti, K.G., Zimmet, P.Z., 1998. Definition, diagnosis and classification of diabetes mellitus and its complications. Part 1: diagnosis and classification of diabetes mellitus provisional report of a WHO consultation. Diabet. Med. 15, 539-553.

Bakker, E.N., Matlung, H.L., Bonta, P., de Vries, C.J., van Rooijen, N., Vanbavel, E., 2008. Blood flow-dependent arterial remodelling is facilitated by inflammation but directed by vascular tone. Cardiovasc. Res. 78, 341-348.

Baron-Menguy, C., Toutain, B., Cousin, M., Dumont, O., Guihot, A.L., Vessieres, E., Subra, J.F., Custaud, M.A., Loufrani, L., Henrion, D., 2010. Involvement of angiotensin II in the remodeling induced by a chronic decrease in blood flow in rat mesenteric resistance arteries. Hypertens. Res. 33, 857-866.

Belin de Chantemele, E.J., Vessieres, E., Guihot, A.L., Toutain, B., Loufrani, L., Henrion, D., 2010. Cyclooxygenase-2 preserves flow-mediated remodelling in old obese Zucker rat mesenteric arteries. Cardiovasc. Res. 86, 516-525.

Belin de Chantemele, E.J., Vessieres, E., Dumont, O., Guihot, A.L., Toutain, B., Loufrani, L., Henrion, D., 2009. Reactive oxygen species are necessary for high flow (shear stress)-induced diameter enlargement of rat resistance arteries. Microcirculation $16,391-402$.

Bolla, M., Matrougui, K., Loufrani, L., Maclouf, J., Levy, B., Levy-Toledano, S., Habib, A., Henrion, D., 2002. p38 mitogen-activated protein kinase activation is required for thromboxane- induced contraction in perfused and pressurized rat mesenteric resistance arteries. J. Vasc. Res. 39, 353-360.

Bouvet, C., Belin de Chantemele, E., Guihot, A.L., Vessieres, E., Bocquet, A., Dumont, O., Jardel, A., Loufrani, L., Moreau, P., Henrion, D., 2007. Flow-induced remodeling in resistance arteries from obese Zucker rats is associated with endothelial dysfunction. Hypertension 50, 248-254.

Buus, C.L., Pourageaud, F., Fazzi, G.E., Janssen, G., Mulvany, M.J., De Mey, J.G., 2001. Smooth muscle cell changes during flow-related remodeling of rat mesenteric resistance arteries. Circ. Res. 89, 180-186.

Dowell, F.J., Henrion, D., Duriez, M., Michel, J.B., 1996. Vascular reactivity in mesenteric resistance arteries following chronic nitric oxide synthase inhibition in Wistar rats. Br. J. Pharmacol. 117, 341-346.

Driss, A., Devaux, C., Henrion, D., Duriez, M., Thuillez, C., Levy, B.I., Michel, J.B., 2000. Hemodynamic stresses induce endothelial dysfunction and remodeling of pulmonary artery in experimental compensated heart failure. Circulation 101, 2764-2770.

Enevoldsen, L.H., Stallknecht, B., Fluckey, J.D., Galbo, H., 2000. Effect of exercise training on in vivo insulin-stimulated glucose uptake in intra-abdominal adipose tissue in rats. Am. J. Physiol. Endocrinol. Metab. 278, E25-E34.

Freidja, M.L., Toutain, B., Caillon, A., Desquiret, V., Lambert, D., Loufrani, L., Procaccio, V., Henrion, D., 2011. Heme oxygenase 1 is differentially involved in blood flowdependent arterial remodeling: role of inflammation, oxidative stress, and nitric oxide. Hypertension 58, 225-231.

Freidja, M.L., Tarhouni, K., Toutain, B., Fassot, C. Loufrani, L, Henrion, D., 2012. The AGE-breaker ALT-711 restores high blood flow-dependent remodeling in mesenteric resistance arteries in a rat model of type 2 diabetes. Diabetes 61, 1562-1572.

Gendron, M.E., Thorin-Trescases, N., Villeneuve, L., Thorin, E., 2007. Aging associated with mild dyslipidemia reveals that COX-2 preserves dilation despite endothelial dysfunction. Am. J. Physiol. Heart Circ. Physiol. 292, H451-H458.

Goodwill, A.G., Frisbee, J.C., 2012. Oxidant stress and skeletal muscle microvasculopathy in the metabolic syndrome. Vasc. Pharmacol. 57, 150-159.

Henrion, D., 2005. Pressure and flow-dependent tone in resistance arteries. Role of myogenic tone. Arch. Mal. Coeur Vaiss. 98, 913-921.

Henrion, D., Laher, I., Laporte, R., Bevan, J.A., 1992. Angiotensin II amplifies arterial contractile response to norepinephrine without increasing $\mathrm{Ca}++$ influx: role of protein kinase C. J. Pharmacol. Exp. Ther. 261, 835-840.

Henrion, D., Dowell, F.J., Levy, B.I., Michel, J.B., 1996. In vitro alteration of aortic vascular reactivity in hypertension induced by chronic NG-nitro-L-arginine methyl ester. Hypertension 28, 361-366.

Herman, W.H., Zimmet, P., 2012. Type 2 diabetes: an epidemic requiring global attention and urgent action. Diabetes Care 35, 943-944.

Hu, G., Qiao, Q., Tuomilehto, J., Balkau, B., Borch-Johnsen, K., Pyorala, K., 2004. Prevalence of the metabolic syndrome and its relation to all-cause and cardiovascular mortality in nondiabetic European men and women. Arch. Intern. Med. 164, 1066-1076.

Iannuzzi, A., De Michele, M., Bond, M.G., Sacchetti, L., Fortunato, G., Salvatore, F., Mattiello, A., Panico, S., Rubba, P., 2005. Carotid artery remodeling in middle-aged women with the metabolic syndrome (from the "Progetto ATENA" study). Am. J. Cardiol. 96, 1162-1165.

Johnson, P.R., Stern, J.S., Horwitz, B.A., Harris Jr., R.E., Greene, S.F., 1997. Longevity in obese and lean male and female rats of the Zucker strain: prevention of hyperphagia. Am. J. Clin. Nutr. 66, 890-903.

Kauffenstein, G., Laher, I., Matrougui, K., Guerineau, N.C., Henrion, D., 2012. Emerging role of $\mathrm{G}$ protein-coupled receptors in microvascular myogenic tone. Cardiovasc. Res. 95, 223-232.

Kurtz, T.W., Morris, R.C., Pershadsingh, H.A., 1989. The Zucker fatty rat as a genetic model of obesity and hypertension. Hypertension 13, 896-901.

Lemkens, P., Nelissen, J., Meens, M.J., Fazzi, G.E., Janssen, G.J., Debets, J.J., Janssen, B.J. Schiffers, P.M., De Mey, J.G., 2012. Impaired flow-induced arterial remodeling in DOCA-salt hypertensive rats. Hypertens. Res. 35, 1093-1101.

Loufrani, L., Levy, B.I., Henrion, D., 2002a. Defect in microvascular adaptation to chronic changes in blood flow in mice lacking the gene encoding for dystrophin. Circ. Res. 91, 1183-1189.

Loufrani, L., Matrougui, K., Li, Z., Levy, B.I., Lacolley, P., Paulin, D., Henrion, D., 2002b. Selective microvascular dysfunction in mice lacking the gene encoding for desmin. FASEB J. 16, 117-119.

Morrison, A., Ramey, D.R., van Adelsberg, J., Watson, D.J., 2007. Systematic review of trials of the effect of continued use of oral non-selective NSAIDs on blood pressure and hypertension. Curr. Med. Res. Opin. 23, 2395-2404.

Onat, A., 2011. Metabolic syndrome: nature, therapeutic solutions and options. Expert Opin. Pharmacother. 12, 1887-1900.

Pourageaud, F., De Mey, J.G., 1997. Structural properties of rat mesenteric small arteries after 4-wk exposure to elevated or reduced blood flow. Am. J. Physiol. 273, H1699-H1706.

Prasad, H., Ryan, D.A., Celzo, M.F., Stapleton, D., 2012. Metabolic syndrome: definition and therapeutic implications. Postgrad. Med. 124, 21-30.

Prewitt, R.L., Rice, D.C., Dobrian, A.D., 2002. Adaptation of resistance arteries to increases in pressure. Microcirculation 9, 295-304.

Rao, C., Adair, T., Bain, C., Doi, S.A., 2012. Mortality from diabetic renal disease: a hidden epidemic. Eur. J. Public Health 22, 280-284.

Retailleau, K., Belin de Chantemele, E.J., Chanoine, S., Guihot, A.L., Vessieres, E., Toutain, B., Faure, S., Bagi, Z., Loufrani, L., Henrion, D., 2010. Reactive oxygen species and cyclooxygenase 2-derived thromboxane A2 reduce angiotensin II type 2 receptor vasorelaxation in diabetic rat resistance arteries. Hypertension 55, 339-344.

Retailleau, K., Toutain, B., Galmiche, G., Fassot, C., Sharif-Naeini, R., Kauffenstein, G., Mericskay, M., Duprat, F., Grimaud, L., Merot, J., Lardeux, A., Pizard, A., Baudrie V., Jeunemaitre, X., Feil, R., Gothert, J.R., Lacolley, P., Henrion, D., Li, Z., Loufrani, L., 2013. Selective involvement of serum response factor in pressure-induced myogenic tone in resistance arteries. Arterioscler. Thromb. Vasc. Biol. 33, 339-346.

Rocic, P., 2012. Why is coronary collateral growth impaired in type II diabetes and the metabolic syndrome? Vasc. Pharmacol. 57, 179-186.

Romanko, O.P., Stepp, D.W., 2005. Reduced constrictor reactivity balances impaired vasodilation in the mesenteric circulation of the obese Zucker rat. Am. J. Physiol. Heart Circ. Physiol. 289, H2097-H2102.

Sanchez, A., Contreras, C., Martinez, P., Villalba, N., Benedito, S., Garcia-Sacristan, A. Salaices, M., Hernandez, M., Prieto, D., 2010. Enhanced cyclooxygenase 2-mediated vasorelaxation in coronary arteries from insulin-resistant obese Zucker rats. Atherosclerosis 213, 392-399.

Schofield, I., Malik, R., Izzard, A., Austin, C., Heagerty, A., 2002. Vascular structural and functional changes in type 2 diabetes mellitus: evidence for the roles of abnormal myogenic responsiveness and dyslipidemia. Circulation 106, 3037-3043.

Stepp, D.W., Boesen, E.I., Sullivan, J.C., Mintz, J.D., Hair, C.D., Pollock, D.M., 2007. Obesity augments vasoconstrictor reactivity to angiotensin II in the renal circulation of the Zucker rat. Am. J. Physiol. Heart Circ. Physiol. 293, H2537-H2542.

Tarhouni, K., Guihot, A.L., Freidja, M.L., Toutain, B., Henrion, B., Baufreton, C., Pinaud, F., Procaccio, V., Grimaud, L., Ayer, A., Loufrani, L., Lenfant, F., Arnal, J.F., Henrion, D. 2013. Key role of estrogens and endothelial estrogen receptor alpha in blood flow-mediated remodeling of resistance arteries. Arterioscler. Thromb. Vasc. Biol. 33, 605-611.

Thomas, G.N., Chook, P., Qiao, M., Huang, X.S., Leong, H.C., Celermajer, D.S., Woo, K.S. 2004. Deleterious impact of "high normal" glucose levels and other metabolic syndrome components on arterial endothelial function and intima-media thickness in apparently healthy Chinese subjects: the CATHAY study. Arterioscler. Thromb. Vasc. Biol. 24, 739-743.

Traupe, T., Lang, M., Goettsch, W., Munter, K., Morawietz, H., Vetter, W., Barton, M. 2002. Obesity increases prostanoid-mediated vasoconstriction and vascular thromboxane receptor gene expression. J. Hypertens. 20, 2239-2245.

van den Akker, J., Schoorl, M.J., Bakker, E.N., Vanbavel, E., 2009. Small artery remodeling: current concepts and questions. J. Vasc. Res. 47, 183-202.

van den Akker, J., VanBavel, E., van Geel, R., Matlung, H.L., Guvenc Tuna, B., Janssen, G.M., van Veelen, P.A., Boelens, W.C., De Mey, J.G., Bakker, E.N., 2011. The redox state of transglutaminase 2 controls arterial remodeling. PLoS One 6, e23067.

Vessieres, E., Freidja, M.L., Loufrani, L., Fassot, C., Henrion, D., 2012. Flow (shear stress)-mediated remodeling of resistance arteries in diabetes. Vasc. Pharmacol. 57, 173-178.

Wild, S., Roglic, G., Green, A., Sicree, R., King, H., 2004. Global prevalence of diabetes: estimates for the year 2000 and projections for 2030. Diabetes Care 27, 1047-1053.

Willette, R.N., Eybye, M.E., Olzinski, A.R., Behm, D.J., Aiyar, N., Maniscalco, K., Bentley, R.G., Coatney, R.W., Zhao, S., Westfall, T.D., Doe, C.P., 2009. Differential effects of p38 mitogen-activated protein kinase and cyclooxygenase 2 inhibitors in a model of cardiovascular disease. J. Pharmacol. Exp. Ther. 330, 964-970.

Yildiz, O., 2007. Vascular smooth muscle and endothelial functions in aging. Ann. N. Y. Acad. Sci. 1100, 353-360. 